\title{
Profil Usaha Industri Garmen "Vandev” di Kota Malang (Studi Usaha Industri Garmen “Vandev” di Kota Malang)
}

\author{
Riska Marianti, Nur Endah Purwaningsih*, Idah Hadijah \\ Universitas Negeri Malang, Jl. Semarang No. 5 Malang, Jawa Timur, Indonesia \\ *Penulis korespondensi, Surel: nur.endah.ft@um.ac.id
}

Paper received: 06-04-2021; revised: 20-04-2021; accepted: 25-04-2021

\begin{abstract}
Managing a business such as a garment must have clear organizational structure, financial management, and production implementation so that company goals can be achieved according to the targets set by a company. The purpose of this research is to describe the business studies in "Vandev" Garments, especially in the production implementation section, which includes the manufacturing process of 3 products, namely jackets, jersey products, and shirt products. In this study, researchers used a descriptive research design with a qualitative approach. Checking the validity of the findings using source triangulation and triangulation techniques Based on the results of the researcher's findings that, all implementation of the production section is in accordance with the Indonesian National Work Competency Standards starting from the process of preparing product samples, the pattern making process, the process of spreading cloth, the process of cutting cloth, the process of numbering the materials, grouping the materials that have been given number, screen printing / embroidery, sewing process, finishing, cleaning clothes from thread remnants (trimming), packaging ironing process. The production implementation process is carried out in each worker's home, so that quality control is carried out every 2 days. Even though production is carried out in each worker's house, it does not change the quality of the product. When the trimming process uses the manual method instead of using a metal detector machine, you must be more careful in checking the product. The product marketing process is not only from within the country but has reached abroad. Suggestions for Garments "Vandev" regarding production management as input to further improve the skills of production employees. The last suggestion is for other researchers that this research can be an input and a reference for similar research but with a more detailed and more detailed discussion of the garment business study, so that it can add new insights for other researchers.
\end{abstract}

Keywords: business studies; garment industry

Abstrak
Mengelola suatu usaha seperti garmen harus jelas struktur organisasinya, pengelolaan keuangan,
serta pelaksanaan produksinya agar tujuan perusahaan bisa tercapai sesuai target yang ditentukan
suatu perusahaan tersebut. Tujuan dari penelitian ini untuk mendeskripsikan studi usaha yang ada
di Garmen "Vandev" terutama pada bagian pelaksanaan produksi meliputi proses pembuatan 3
produk yaitu jaket, produk jersey, dan produk kemeja. Pada penelitian ini peneliti menggunakan
rancangan penelitian deskriptif dengan pendekatan kualitatif. Pengumpulan data yang diperoleh
peneliti mulai dari proses wawancara 2 karyawan dan 1 pemilik garmen, observasi saat proses
produksi berlangsung, serta dokumentasi saat proses produksi. Pengecekan keabsahan temuan
menggunakan triangulasi sumber dan triangulasi teknik. Berdasarkan hasil temuan penelti bahwa,
semua pelaksanaan bagian produksi telah sesuai dengan Standar Kompetensi Kerja Nasional
Indonesia mulai dari proses menyiapkan contoh produk (sample), proses pembuatan pola, proses
mengelar kain, proses memotong kain, proses penomeran pada bahan, pengelompokkan bahan yang
sudah diberi nomer, sablon/bordir, proses menjahit, finishing, membersihkan pakaian dari sisa-sisa
benang (trimming), proses penyetrikaan pengemasan. Proses pelaksanan produksi dilakukan di
rumah masing-masing pekerja, sehingga quality control dilakukan setiap 2 hari sekali. Meskipun
produksi dilakukan di masing-masing rumah pekerja tidak merubah kualitas produk tersebut. Saat
proses trimming menggunakan cara manual bukan menggunakan mesin metal detector sehingga
harus lebih teliti dalam memeriksa produknya. Proses pemasaran produk bukan hanya dari dalam
negeri melainkan sudah sampai ke luar negeri. Saran bagi Garmen "Vandev" mengenai pengelolaan


produksi sebagai masukan untuk lebih meningkatkan keterampilan para karyawan bagian produksi. Saran yang terakhir yaitu bagi peneliti lain bahwa penelitian ini bisa menjadi masukan serta menjadi referensi untuk penelitian sejenisnya namun dengan pembahasan yang lebih diperinci dan lebih detail mengenai studi usaha garmen, sehingga dapat menambah wawasan baru bagi peneliti lainnya.

Kata kunci: studi usaha; industri garmen

\section{Pendahuluan}

Garmen merupakan salah satu bentuk usaha dibidang busana yang memproduksi pakaian jadi dalam skala besar sehingga dalam proses pengerjaannya memerlukan pekerja (karyawan) yang lebih banyak. Garmen "Vandev" merupakan perusahaan yang bergerak di bidang busana, produ yang dihasilkan produk berupa seragam, T-shirt, kemeja, jaket, katelpak, jas, jersey dalam jumlah banyak. Garmen "Vandev" berdiri pada tahun 2010 dan telah memproduksi ribuan produk. letak garmen berada di Jl. Simpang Gajayana No. 12 Dinoyo, Kecamatan Lowokwaru, Kota Malang.

Peneliti ingin meneliti salah satu garmen di Kota Malang yaitu Garmen "Vandev", dimana Garmen "Vandev" merupakan salah satu garmen yang memiliki rating bagus dalam pemasaran khususnya di media sosial. Pemasaran produknya bukan hanya dari dalam negeri melainkan sudah sampai luar negeri seperti, Timor Leste, Singapura, Malaysia, Hongkong. Proses pemasaran pada Garmen "Vandev" melalui penyebaran brosur, pamflet ke kampus-kampus dan ke sekolah lainnya selain itu pemasaran dilakukan melalui media sosial seperti website, instagram, google bisnis dan facebook.

Selain dari segi pemasarannya, produk yang dihasilkan merupakan produk yang berkualitas bagus seperti jahitannya rapi dan halus, karena disini lebih mengutamakan kualitas produknya. Pengelolaan usaha di Garmen "Vandev" tergolong bagus mulai dari perencanaan, pengorganisasia garmen, pelaksanaan sampai pemasarannya sehingga tujuan perusahaan dapat tercapai dan didukung oleh para pekerja yang berkompetensi di bidangnya. Kompetensi yang telah dimiliki oleh pekerja sesuai dengan acuan standar kompentensi pekerja pada Custome Made SKKNI Nomor 90 Tahun 2010 tentang Penetapan SKKNI Sektor Industri Tekstil dan Barang Jadi Tekstil Bidang Garmen Bidang Custome Made Sub Bidang Custom Made Wanita, maka proses pelaksanaan sesuai dengan fungsi kompetensi industri garmen.

Profil usaha yang akan diteliti di Garmen "Vandev" adalah a) perencanaan usaha mulai dariperencanaan modal, perencanaan alat dan bahan, perencanaan tenaga kerja (sumber daya manusia), perencanaan tempat usaha garmen, b) pengorganisasian meliputi struktur organisasi, c) pelaksanaan produksi mulai dari proses pembuatan produk jaket, jersey, kemeja mulai dari desain, pembuatan pola, proses mengelar kain, proses memotong kain, proses penomeran pada bahan, pengelompokkan bahan yang sudah diberi nomer, sablon/bordir, proses menjahit, finishing, membersihkan pakaian dari sisa-sisa benang (trimming), proses penyetrikaan pengemasan, dan sampai d) pemasaran. Pada tahap pelaksanaan peneliti lebih menekankan pada proses pembuatan jaket, jersey, dan kemeja. 


\section{Metode}

Jenis penelitian "Studi Usaha Industri Garmen "Vandev" di Kota Malang" merupakan penelitian deskriptif dengan pendekatan kualitatif. Lokasi penelitian berada di Jl.Simpang Gajayana No.12 Dinoyo, Kecamatan Lowokwaru, Kota Malang. Sumber data yang digunakan dalam penelitian ini adalah data primer dan sumber data sekunder. Teknik pengumpulan data kualitatif dengan cara melakukan wawancara melalui sumber data yang akan diteliti, observasi, dan dokumentasi. Pengecekan keabsahan temuan dengan menggunakan triangulasi teknik seperti wawancara, observasi, dokumentasi seperti pembuatan desain menggunakan aplikasi corel draw, pembuatan pola menggunakan aplikasi corel draw, pembuatan pola, proses mengelar kain, proses memotong kain, proses penomeran pada bahan, pengelompokkan bahan yang sudah diberi nomer, sablon/bordir, proses menjahit, finishing, membersihkan pakaian dari sisa-sisa benang (trimming), proses penyetrikaan, proses pengemasan sedangkan untuk triangulasi sumber yaitu sumber data yang diambil peneliti yaitu pemilik garmen, pengawas, dan karyawan bagian produksi.

\section{Hasil dan Pembahasan}

\subsection{Perencanaan}

Modal usaha Garmen "Vandev" merupakan milik sendiri/pribadi. Modal usaha digunakan untuk menyewa tempat di Dinoyo dan untuk proses produksinya dilakukan dirumah masing-masing karyawan. Alat yag digunakan dalam proses produksi seperti mesin obras, mesin jahit, mesin overdeck, mateline, gunting, kapur jahit, benang jahit, benang obras, pendedel, dan alat untuk menyablon. Produk yang dihasilkan disini ada T-shirt, jaket, kemeja, polo, sweater, jersey, jas/almamater, seragam, katelpak. Jumlah tenaga kerja yang ada di Garmen "Vandev" disini kurang lebih ada 22 karyawan mulai dari bagian memotong bahan, sablon, menjahit, quality control, pengemasan. Setiap karyawan memilik tanggung jawab masing-masing sesuai dengan bidangnya. Bagian memotong bahan, sablon dan pengemasan dilakukan di garmen sedangkan bagian sewing dilakukan dirumah masing-masing karyawan. Garmen "Vandev" mempunyai 2 tempat usaha di Malang untuk yang berada di Malang tempat usaha masih menyewa.

\subsection{Pengorganisasian}

Struktur organisasi di Garmen "Vandev" meliputi pemimpin perusahaa, wakil perusahaan, manager produksi, manager pemasaran. Alur produksi di Garmen "Vandev" mulai dari pembuatan desain menggunakan aplikasi corel draw, pembuatan pola manual dan aplikasi corel draw, pembuatan pola, proses mengelar kain, proses memotong kain, proses penomeran pada bahan, pengelompokkan bahan yang sudah diberi nomer, sablon/bordir, proses menjahit, finishing, membersihkan pakaian dari sisa-sisa benang (trimming), proses penyetrikaan pengemasan.

\subsection{Pelaksanaan}

\subsubsection{Teknik Pembuatan Jersey}

Desain jersey, (b) Persiapan bahan (c) Pembuatan pola, (d) Cutting, (e) Sewing: (1) Membordir, (2) Menjahit sisi badan, (3) Menjahit badan TM, TB dan sisi, (4) Menjahit bahu dan kelim, (5) Menjahit lingkar kerung lengan, (6) Menjahit krah V, (7) Menjahit sisi celana, (8) 
Menyambung sisi celana, 9) Menjahit ban pinggang, (10) Menjahit ban pinggang ke celana, (11) Menjahit pesak celana, (12) Menjahit kelim celana, (f) Finishing: (1) (Trimming), (2) Pemeriksaan kualitas (3) pengemasan.

\subsubsection{Teknik Pembuatan Jaket}

(a) Desain jaket bomber, (b) Persiapan bahan utama dan bahan pelengkap, (c) Pembuatan pola, (d) Proses cutting, (e) Proses menjahit: (1) Membordir jaket, (2) Menjahit saku vest, (3) Menjahit bagian bahu dan sisi, (4) Menjahit lengan dan kerung lengan, (5) Menjahit saku vest furing, (6) Menjahit bahu dan sisi, (7) Menjahit lengan dan kerung lengan, (8) Menjahit rip lengan, (9) Menjahit kelim bawah dan zipper, (10) Menjahit krah, (f) Proses finishing: (1) (Trimming), (2) Pemeriksaan kualitas, (3) pengemasan..

\subsubsection{Teknik Pembuatan Kemeja}

(a) Desain Kemeja, (b) Pembuatan Pola, (c) Proses memotong bahan, (d) Proses menjahit: (1) Membordir Kemeja, (2) Menjahit Saku Tempel, (3) Menjahit Variasi Lidah Kancing, (4) Menjahit Variasi TB, (5) Menjahit Bahu, Belahan, Label dan Sisi, (6) Menjahit Lengan (Variasi, dan Kelim), (7) Menjahit Krah, (8) Menjahit Kelim Bawah. (f) Finishing: (1) (Trimming), (2) Pemeriksaan Kualitas Kemeja (Quality Control), (3) pengemasan.

Menurut (Radyanto 2004) alur produksi pada industri garmen sebagai berikut: Desain produk, merupakan suatu gambaran sebuah produk (barang) yang dirancang untuk khusus untuk memenuhi kepuasan konsumen. Desain di Garmen "Vandev" menggunakan aplikasi corel draw agar desain yang diberikan ke karyawan lebih detail dan mudah dipahami oleh semua karyawan. Proses membuat desain sudah sesuai dengan Standar Kompetensi Kerja Nasional Indonesia (SKKNI) karena pembuatan desain dilakukan atas dasar permintaan konsumen mulai dari menganalisis jenis kain yang digunakan, ukuran, warna kain/motif, dan model produknya.

Proses pattern maker di Garmen "Vandev" sudah sesuai dengan Standar Kompetensi Kerja Nasional Indonesia (SKKNI) pembuatan pola dilakukan dengan menggunakan komputer dan cara manual, untuk grading pola di SKKNI menggunakan komputer begitupun juga di Garmen "Vandev" karena dengan menggunakan komputer mempermudah pembuatan pola dengan lebih cepat. Proses mengelar kain (spreading) yang ada di Garmen "Vandev" sudah sesuai dengan Standar Kompetensi Kerja Nasional Indonesia (SKKNI), ketika proses mengelar kain (spreading) dilakukan langkah pertama harus mempertimbangkan jenis kain, motif kain dan jumlah gelaran kain agar tidak terjadi kesalahan dan sesuai dengan instruksi kerja pada garmen. Proses memotong kain (cutting) yang ada di Garmen 'Vandev' sudah sesuai dengan Standar Kompetensi Kerja Nasional Indonesia (SKKNI) dengan meletakkan pola pada kain yang sudah digelar di meja potong dan memberi tanda pada kain untuk kampuh jahit. Proses selanjutnya adalah memberi nomor/kode (numbering) di Garmen "Vandev" sudah sesuai dengan Standar Kompetensi Kerja Nasional Indonesia (SKKNI), ketika proses memotong kain selesai setiap potongan kain diberi kode agar mempermudah proses menjahit sesuai ukuran dan kode pada potongan kain sehingga tidak terjadi kesalahan ukuran ketika menjahit.

Proses pengelompokkan kain (bundling) dilakukan agar potongan kain yang sudah diberi kode atau keterangan di kelompokkan berdasarkan ukuran dan proses pengelompokkan kain (bundling) di Garmen "Vandev" sesuai dengan Standar Kompetensi 
Kerja Nasional Indonesia (SKKNI). Proses bordir dilakukan di luar Garmen "Vandev" karena keterbatasan tempat sehingga dilakukan diluar garmen, dan ketika proses produksi berlangsung bagian quality control selalu memonitor setiap proses produksi meskipun hanya 3 hari sekali ke rumah karyawan masing-masing. Proses menjahit (sewing) dilakukan di rumah masing-masing karyawan karena keterbataan tempat dan dalam proses menjahit (sewing) setiap karyawan diberi darft mengenai intruksi pembuatan produk sehingga mempermudah karyawan dalam melakukan proses produksi. Proses menjahit (sewing) di Garmen "Vandev" sesuai dengan Standar Kompetensi Kerja Nasional Indonesia (SKKNI) dengan menjahit setiap komponen pakaian yang dijahit sesuai standar kualitas produk.

Ketika bagian quality control memonitor proses produksi di rumah karyawan dengan mengamati dan mengumpulkan informasi hasil produksi tersebut untuk melihat seberapa jauh proses produksi dilakukan sesuai target yang sudah ditetepkan garmen. Ketika menjahit kemeja setiap karyawan memiliki teknik tersendiri untuk memudahkan dan mempercepat proses produksi, seperti halnya menjahit krah kemeja harus benar-benar diperhatikan agar ketika menjahit krah tidak miring dan tepat di bagian TM karena kemeja akan terlihat rapi apabila krahnya rapi dan tegak maka dari itu sangat diperhatikan dalam pembuatan krah. Menurut Astuti (2010:5) ketika menjahit krah usahakan krah menjadi lancip pada bagian daun krah agar krah menjadi tegak dan rapi.

Proses finishing yang terdapat pada SKKNI mulai dari membersihkan sisa-sisa benang (trimming) yang dilakukan sesuai dengan instruksi kerja garmen dengan memastikan tidak ada yang terpotong dan bersih dari sisa-sisa benang yang menempel pada produk. Proses pengepresan di SKKNI terlebih dahulu memeriksa kualitas produk sesuai standar dan produk diperiksa dengan menggunakan mesin metal detector agar tidak ada logam seperti potongan jarum yang masih menempel pada produk. Menurut (Radyanto 2004) finishing merupakan bagian tahap akhir dari urutan proses produksi, dimana proses finishing mempunyai tugas penting dalam memastikan bahwa produk yang akan dikirim dalam keadaan yang baik dan sempurna dari segi mutu, jahitan, penampilan dan kesesuaian desain yang telah ditentukan konsumen.

Tahap yang terakhir adalah proses pengemasan (packing). Proses pengemasan Garmen "Vandev" sudah sesuai dengan Standar Kompetensi Kerja Nasional Indonesia (SKKNI) karena pengemasan produk menggunakan kemasan plastik dan menggunakan kantung plastik jika produk dibawah 100 pcs dan untuk produk diatas 100 pcs menggunakan karung agar produk tetap terjaga kebersihan dan kualitas produknya sampai ketangan konsumen. Berdasarkan hasil penelitian diatas, bahwa proses pelaksanaan di Garmen "Vandev" sudah sesuai dengan kriteria unjuk kerja SKKNI hanya saja beberapa yang belum sesuai dengan kriteria unjuk kerja seperti mendeteksi adanya logam atau potongan jarum pada pakaian menggunakan mesin metal detector, meskipun tidak menggunakan mesin metal detector produk yang dihasilkan tetap berkualitas bagus, karena bagain quality control terus memantau dan mengontrol produk ssebelum produk dikirim ke tangan konsumen.

\section{Simpulan}

Bahwa profil usaha Garmen "Vandev" ditinjau dari perencanaan perusahaan tempat usaha garmen masih menyewa dan modal usaha menggunakan modal pribadi. Pada proses pelaksanaan sudah sesuai dengan kriteria unjuk kerja SKKNI mulai dari segi desain, pembuatan pola, proses mengelar kain, proses memotong kain, proses penomeran pada bahan, 
pengelompokkan bahan yang sudah diberi nomer, sablon/bordir, proses menjahit, finishing, membersihkan pakaian dari sisa-sisa benang (trimming), proses penyetrikaan pengemasan. Proses menjahit dilakukan di rumah masing-masing pekerja karena tempat untuk produksi tidak mencukupi jika dilakukan di garmen tersebut dan untuk proses finishing sendiri proses pengerjaannya dilakukan secara manual bukan menggunakan mesin metal detactor yang berfungsi untuk mengecek apakah produk aman dari benda berhaya seperti potongan jarum yang menempel pada suatu produk. Meskipun proses produksinya di luar garmen produk yang dihasilkan tetap berkualitas dan sesuai dengan permintaan konsumen. Pada proses pemasaran di Garmen "Vandev" tergolong bagus khususnya pemasaran di media sosial bukan hanya di dalam negeri melainkan sampai ke luar negeri dengan begitu produk yang dihasilkan juga tergolong berkualitas bagus.

\section{Daftar Rujukan}

Amirulloh, A. (2015). Pengantar Manajemen Fungsi Proses Pengendalian. Jakarta: Mitra Wacana Media.

Arikunto, S. (2002). Proses Penelitian Suatu Pendekatan Praktik. Jakarta: PT Rineka Cipta.

Arifin, R \& Muhammad, H. (2016). Pengantar Manajemen. Malang: Empatdua.

Astuti, A.(2010). Modul Mata Kuliah Busana Pria. Jakarta : Universitas Pendidikan Indonesia.

Departemen Menteri Ketenagakerjaan Republik Indonesia. (2015). Penetapan Standart Kompetensi Kerja Nasional Indonesia Kategori Industri Pengolahan Golongan Pokok Industri Pakaian Jadi Bidang Produksi Pakaian Jadi Massal. Jakarta.

Ekawardhana, A. W. (2013). Pengelolaan dan Pengembangan Bisnis Garment pada Indo Garment Surabaya. Agora, 1(1), 544-553.

Firdaus, A. M. (2012). Metode Penelitian. Tangerang: Jelajah Nusa.

Fuad, A., \& Nugroho, K. S. (2014). Panduan praktis penelitian kualitatif. Yogyakarta: Graha Ilmu.

Hasibuan, M. S. (2009). Manajemen Dasar, Pengertian, dan Masalah, Edisi Revisi. Jakarta: Bumi Aksara.

Indriastuti, B. (2009). Kajian Tentang Pengelolaan Usaha Pada Industri Kecil Konveksi di Desa Tempursari Kecamatan Ngawen Kabupaten Klaten (Doctoral dissertation, Universitas Negeri Semarang).

Lindhawati, E. (2008). Pengelolaan Usaha Konveksi di Kecamatan Wedi Kabupaten Klaten. Universitas Negeri Yogyakarta, Yogyakarta.

Kotler, P. (1984). Manajemen Pemasaran Analisis Perencanaan dan Pengendalian, Edisis Kelima. Jakarta: Penerbit Erlangga.

Manap, A. (2016). Revolusi Manajemen Pemasaran. Jakarta: mitra wacana media.

Moleong, L.( 2014). Metode Penelitian Kualitatif. Bandung: PT Remaja Rosdakarya.

Sugiyono, S. (2012). Metode Penelitian Kuantitatif Kualitatif dan R\&D. Bandung: Alfabet.

Sunarto, S. (2003). Pengantar Bisnis. Yogyakarta: AMUS.

Syukron, A. (2014). Pengantar Manajemen Industri, Edisi Pertama. Yogyakarta: Graha Ilmu.

Wibowo, S. (2009). Pengantar Manajemen Bisnis Introduction To Business Management. Bandung : Politeknik Telkom 